\title{
Alanyl-glutamine attenuates 5-fluorouracil-induced intestinal mucositis in apolipoprotein E-deficient mice
}

\author{
C.V. Araújo ${ }^{1}$, C.R. Lazzarotto ${ }^{2}$, C.C. Aquino ${ }^{1}$, I.L. Figueiredo ${ }^{1}$, T.B. Costa ${ }^{1}$, L.A. de Oliveira Alves ${ }^{1}$ \\ R.A. Ribeiro ${ }^{3}$, L.R. Bertolini ${ }^{2}$, A.A.M. Lima ${ }^{4}$, G.A.C. Brito ${ }^{3}$ and R.B. Oriá ${ }^{1}$ \\ ${ }^{1}$ Laboratório da Biologia da Cicatrização, Ontogenia e Nutrição de Tecidos, INCT - Instituto de Biomedicina do Semiárido \\ Brasileiro, Faculdade de Medicina, Universidade Federal do Ceará, Fortaleza, CE, Brasil \\ ${ }^{2}$ Laboratório de Biologia Molecular e do Desenvolvimento, Universidade de Fortaleza, Fortaleza, CE, Brasil \\ ${ }^{3}$ Laboratório da Inflamação e Câncer, INCT - Instituto de Biomedicina do Semiárido Brasileiro, Faculdade de Medicina, \\ Universidade Federal do Ceará, Fortaleza, CE, Brasil \\ ${ }^{4}$ Laboratório de Doenças Infecciosas, INCT - Instituto de Biomedicina do Semiárido Brasileiro, Faculdade de Medicina, \\ Universidade Federal do Ceará, Fortaleza, CE, Brasil
}

\begin{abstract}
Apolipoprotein $E(A P O E=$ gene, apoE = protein) is a known factor regulating the inflammatory response that may have regenerative effects during tissue recovery from injury. We investigated whether apoE deficiency reduces the healing effect of alanyl-glutamine (Ala-GIn) treatment, a recognized gut-trophic nutrient, during tissue recovery after 5-FU-induced intestinal mucositis. APOE-knockout $\left(\mathrm{APOE}^{--}\right)$and wild-type $\left(\mathrm{APOE}^{+/+}\right)$C57BL6J male and female mice $(\mathrm{N}=86)$ were given either AlaGln $(100 \mathrm{mM})$ or phosphate buffered saline (PBS) by gavage 3 days before and 5 days after a 5-fluorouracil (5-FU) challenge $(450 \mathrm{mg} / \mathrm{kg}$, via intraperitoneal injection). Mouse body weight was monitored daily. The 5-FU cytotoxic effect was evaluated by leukometry. Intestinal villus height, villus/crypt ratio, and villin expression were monitored to assess recovery of the intestinal absorptive surface area. Crypt length, mitotic, apoptotic, and necrotic crypt indexes, and quantitative real-time PCR for insulinlike growth factor-1 (IGF-1) and B-cell lymphoma 2 (Bcl-2) intestinal mRNA transcripts were used to evaluate intestinal epithelial cell turnover. 5-FU challenge caused significant weight loss and leukopenia $(P<0.001)$ in both mouse strains, which was not improved by Ala-GIn. Villus blunting, crypt hyperplasia, and reduced villus/crypt ratio $(P<0.05)$ were found in all 5 -FUchallenged mice but not in PBS controls. Ala-GIn improved villus/crypt ratio, crypt length and mitotic index in all challenged mice, compared with PBS controls. Ala-GIn improved villus height only in APOE ${ }^{-/}$mice. Crypt cell apoptosis and necrotic scores were increased in all mice challenged by $5-\mathrm{FU}$, compared with untreated controls. Those scores were significantly lower in Ala-GIn-treated APOE ${ }^{+/+}$mice than in controls. Bcl-2 and IGF-1 mRNA transcripts were reduced only in the APOE ${ }^{-1-}$ challenged mice. Altogether our findings suggest APOE-independent Ala-GIn regenerative effects after 5-FU challenge.
\end{abstract}

Key words: Apolipoprotein E; 5-Fluorouracil; Alanyl-glutamine; mucositis; mice

\section{Introduction}

5-Fluorouracil (5-FU) is the most frequently prescribed anticancer drug for clinical treatment of various types of cancer, including colorectal cancer (1,2). 5-FU may lead to intestinal mucositis, villus atrophy, and crypt necrosis as a result of mucosal tissue damage due to inflammatory cell infiltration, proinflammatory cytokine release and edema (3). A rapid increase in epithelial cell apoptosis and arrest of cell division within the intestinal crypts can lead to a breakdown of the intestinal epithelial barrier and continuous luminal bacterial translocation (4,5). 5-FU-induced intestinal mucositis is clinically relevant because it may disrupt the intestinal absorptive surface, causing nutrient malabsorption and a poor health condition that may lead to therapy failure if associated with diarrhea and vomiting (6). Such side effects may be aggravated by the presence of other simultaneous inflammatory bowel diseases (7).

Glutamine is considered to be a critical gut-trophic nutrient that has been shown to protect against intestinal injury in experimental models $(8,9)$ and to be beneficial in clinical studies enrolling children with malnutrition and diarrhea in the developing world $(9,10)$. Glutamine has been also implicated in the regulation of the innate immune

Correspondence: R.B. Oriá: <oria@ufc.br>.

Received September 10, 2014. Accepted December 11, 2014. First published online April 28, 2015. 
system (11), the inflammatory process (12) and intestinal epithelial viability following Clostridium difficile toxin A (13) and 5-FU-challenge (14).

Recently, our group has documented anti-inflammatory and healing activities of the apolipoprotein E COG 133 mimetic peptide in a model of 5-FU-induced intestinal mucositis in vivo and in vitro. This suggests that apolipoprotein $E$ (apoE), a cholesterol-carrier protein, is involved in the inflammatory process and intestinal epithelial restitution following 5-FU-induced tissue damage (15). In addition, we have demonstrated that APOE4 target replacement mice were protected against Cryptosporidium parvum infection by balancing the inflammatory responses (16). The APOE4 gene was also found to benefit the cognitive development of children with heavy diarrhea burdens (17) and may influence pro-cognition effects of gut-trophic nutrients in children at risk of diarrhea and malnutrition (18).

Alanyl-glutamine (Ala-Gln) is a glutamine dipeptide, but is more soluble and stable than glutamine. In order to assess whether apoE deficiency jeopardized the healing effects of Ala-GIn treatment during tissue recovery after 5-FU-induced intestinal mucositis, we treated 5-FUchallenged APOE knockout $\left(\mathrm{APOE}^{-/}\right)$and wild-type $\left(\mathrm{APOE}^{+/+}\right)$mice with Ala-GIn $(100 \mathrm{mM})$ and monitored parameters of intestinal surface recovery and crypt cell integrity and renewal.

\section{Material and Methods}

\section{5-Fluorouracil}

5-Fluorouracil (Eurofarma ${ }^{\circledR}$, Brazil) was obtained from the Laboratório de Farmacologia da Inflamação e do Câncer (LAFICA), Universidade Federal do Ceará (UFC) and used to induce intestinal mucositis. Alanyl-glutamine (Ala-GIn) was obtained from Rexim (Courbevoie, France). A 100 mM stock solution was prepared in phosphate buffered saline (PBS) consisting of $0.9 \% \mathrm{NaCl}, 10 \mathrm{mM} \mathrm{Na} 2 \mathrm{HPO}_{4}, 10 \mathrm{mM}$ $\mathrm{NaH}_{2} \mathrm{PO}_{4}, \mathrm{pH} 7.4$.

\section{Animals}

C57BL6J wild-type and APOE-knockout $\left(\mathrm{APOE}^{-/-}\right)$male and female mice were obtained from the Universidade de São Paulo transgenic vivarium and housed in the Instituto de Biomedicina at the Universidade Federal do Ceará (UFC). When obtained, experimental mice weighed 20$25 \mathrm{~g}$. All experimental protocols were in compliance with the Brazilian College for Animal Experimentation (COBEA) and the Animal Care and Use Committee Guidelines of the UFC. Experimental mice were kept in polyethylene boxes with free access to animal chow and water until sacrificed, and maintained on a 12-h light-dark cycle. The mice were randomly allocated to 6 treatment groups: $5-\mathrm{FU}:(n=15$ for $\mathrm{APOE}^{+/+}$and $\mathrm{n}=14$ for $\mathrm{APOE}^{-/-}$mice), Ala-GIn $(\mathrm{n}=16$ for $\mathrm{APOE}^{+/+}$and $n=13$ for $\mathrm{APOE}^{-/-}$mice), or PBS $(\mathrm{n}=15$ for $\mathrm{APOE}^{+/+}$and $n=13$ for $\mathrm{APOE}^{-/-}$mice).

\section{Mucositis induction, Ala-GIn treatment and tissue collection}

For the induction of intestinal mucositis, a single intraperitoneal (ip) dose of $5-\mathrm{FU}(450 \mathrm{mg} / \mathrm{kg})$ was administered to both wild-type and $\mathrm{APOE}^{-/-}$mice on the 1 st day of the experiment; control animals received PBS. Experimental mice received either $100 \mathrm{mM}$ of Ala-GIn ( $0.5 \mathrm{~mL}$ /animal) or PBS control solution given by oral gavage 3 days prior to 5-FU administration and for 5 days afterwards. Animals were weighed daily and were euthanized on day 6 with an overdose of ketamine/ xylazine solution. After sacrifice, 1-cm-long ileal segments were harvested, immediately frozen in liquid nitrogen and stored in a $-80^{\circ} \mathrm{C}$ freezer until use. Additional $1-\mathrm{cm}$ ileal segments were fixed in formaldehyde and stored for further histology processing.

\section{Blood leukocyte counts}

In order to evaluate 5-FU cytotoxicity, blood leukocyte counts were carried out in Neubauer chambers. Mice were lightly anesthetized with ether, and peripheral blood was drawn up in a capillary tube inserted into the orbital plexus. The blood was mixed with a $3 \%$ acetic acid solution (Turk's solution) at a 1:20 ratio for loading into the chambers; leukocyte counts were recorded as cells $/ \mathrm{mm}^{3}$.

\section{Analyses of intestinal surface recovery}

Intestinal morphometric analysis. Morphometric analysis was carried out in low magnification photomicrographs of hematoxylin and eosin (H\&E)stained tissue using the Image $\mathrm{J}$ software 1.4 (National Institutes of Health, USA) after proper calibration. Villus height was measured in at least 10 villus longitudinal sections (4 animals per group). Intestinal crypts were severely affected by 5 -FU treatment in our regimen protocol; therefore crypt length measurements were not considered.

Villin protein expression by immunoblotting. Western blots of ileal villin were used to evaluate the brush border of the intestinal absorptive surface. In brief, intestinal segments were harvested and immediately frozen in liquid nitrogen. Thawed specimens were pulverized in glass homogenizers containing lysis buffer and then transferred to test tubes with protease inhibitor and centrifuged at $17,530 \mathrm{~g}$ for $10 \mathrm{~min}$. Supernatants were assayed using the bicinchoninic acid method (BCA Protein Assay Kit; Pierce, USA) to standardize $50 \mu \mathrm{g}$ of protein product in each well. Samples were loaded onto $10 \%$ denaturing polyacryamide gels (Amersham Biosciences, UK). The gels were then transferred onto nitrocellulose membranes. Membranes were blocked overnight ( $5 \%$ fat-free milk solution), incubated with rabbit villin $(1: 500)$ or $\beta$-actin $(1: 1000)$ antibody for $1 \mathrm{~h}$, rinsed 3 times in rinsing buffer, incubated in a biotinylated secondary antibody (horseradish peroxidase, 1:1000), and then rinsed as described above. Each membrane was washed with coumaric acid, luminol, Tris, and $\mathrm{H}_{2} \mathrm{O}_{2}$ and exposed to 
Table 1. Criteria used to determine intestinal crypt scoring of experimental mice challenged by 5-FU-induced mucositis.

\begin{tabular}{ll}
\hline Score & \multicolumn{1}{c}{ Histopathological characteristics } \\
\hline 0 & $\begin{array}{l}>90 \% \text { of crypts showing normal cytoarchitecture and size without enlargement and hyperplasia. Well-defined gland base. } \\
\text { Intact Paneth and goblet cells with conspicuous cytoplasmatic granules. } \\
>70 \% \text { exhibiting crypt hyperplasia and enlargement. Normal cytoarchitecture without necrotic change. Intact Paneth and } \\
\text { goblet cells with conspicuous cytoplasmatic granules. }\end{array}$ \\
2 & $\begin{array}{l}\text { Similar to degree 1, however } 30 \% \text { of the normal crypts showing cytoarchitecture changes and necrotic lesion at its base. } \\
\text { Infiltration of inflammatory cells, with the possible presence of Paneth and goblet cells but without conspicuous } \\
\text { cytoplasmatic granules. } \\
\text { Between } 50 \text { and } 70 \% \text { crypts exhibiting necrotic changes at the base of the crypt with infiltration of inflammatory cells. The } \\
\text { remaining crypts show hyperplasia and enlargement. Absence of Paneth and goblet cells. } \\
\text { > } 70 \% \text { crypts exhibiting necrotic changes at the base with infiltration of inflammatory cells. Absence of Paneth and goblet } \\
\text { cells. }\end{array}$ \\
\hline
\end{tabular}

Kodak X-Omat AR film (Kodak, USA). Western blot bands were identified and the densitometry analyzed by Image $\mathrm{J}$ (Media Cybernetics, USA), and are reported as villin/ $\beta$-actin ratio.

\section{Crypt integrity and function}

Mitotic and apoptotic indexes. To evaluate the role of Ala-GIn in healing of the injured small intestinal mucosa, we determined the mitotic index by counting well-defined mitotic figures in the crypt bases. An investigator who was blinded to the study treatment did the counts. The number of mitotic figures per crypt were scored in $20 \mathrm{H} \& \mathrm{E}$ stained longitudinal crypt sections from each mouse intestine ( $n=4$ mice per group). The crypts were selected by identifying the proliferative glands. The absolute values were averaged to produce the mitotic index of each group. The apoptotic index was investigated by blindly counting the apoptotic bodies per crypt in at least $20 \mathrm{H} \& \mathrm{E}$ stained longitudinal crypt sections from each mouse intestine ( $n=4$ mice per group). Measurements were made by light microscopy (Olympus CX3, Japan) using an immersion objective $(1000 \times)$ and image acquisition (Q-Color 3, Olympus). Crypt mitotic figures included classical mitosis phases or cytokinesis; apoptotic figures were identified as eosinophilic bodies with a fragmented nucleus and were generally found near or inside the intestinal gland lumen, as described elsewhere (5).

Crypt necrotic scores. Crypt necrotic scores were determined by light microscopy (Olympus CX31) in H\&Estained slides at both low and high magnification by an experienced histologist who was blinded to the experimental treatments. Table 1 lists the criteria used for evaluation and scoring of intestinal crypts. A lower score indicates normal crypt architecture with secretory cells having conspicuous cytoplasmic granules.

Table 2. Sequence of the primers used in the study.

\section{IGF-1 and BCL-2 quantitative real-time PCR (qPCR)}

Samples were taken immediately from necropsied animals and frozen in liquid nitrogen. After freezing, the samples were stored at $-80^{\circ} \mathrm{C}$ until analysis. Samples were thawed and total RNA was extracted using Qiagen RNeasy mini kit (QIAGEN Biotecnologia Brasil Ltda, Brazil) according to the manufacturer's instructions. RNA concentration was quantified and checked spectrophotometrically (Biophotometer; Eppendorf, Germany) for purity by UV absorbance at $260 \mathrm{~nm}$ and $280 \mathrm{~nm}$ (A260:280 ratio). Synthesis of cDNA by reverse transcriptase $P C R$ was performed using the SuperScript III First-Strand Synthesis System SuperMix (Invitrogen, Life Technologies, Brazil) with the use of oligo (dT) as primers. cDNA was used in qPCR for measuring IGF-1 and BCL-2 expression compared with actin expression (used as the housekeeping gene). The primers for murine IGF-1 and BCL-2 were purchased from Invitrogen and their nucleotide sequences are shown in Table 2. Amplification consisted of $10 \mathrm{~min}$ at $95^{\circ} \mathrm{C}$, followed by 40 cycles of $25 \mathrm{~s}$ at $95^{\circ} \mathrm{C}, 25 \mathrm{~s}$ at the respective annealing temperature for each pair of primers $\left(60^{\circ} \mathrm{C}\right)$, and $20 \mathrm{~s}$ at $72^{\circ} \mathrm{C}$, followed by 40 cycles of $10 \mathrm{~s}$ starting at $75^{\circ} \mathrm{C}$, with $0.5^{\circ} \mathrm{C}$ increments for the melt curve. Fluorescence was measured during the annealing step of each cycle. The relative gene expression was determined using the $2^{-\Delta \Delta C t}$ method.

\section{Statistical analysis}

Results are reported as means \pm SEM, except for Table 3 where data are reported as means \pm SD. ANOVA followed by the Bonferroni correction was applied to compare multiple groups. The unpaired Student's $t$-test was used for twogroup comparisons. The nonparametric Mann-Whitney test was used to determine the significance of differences in

\begin{tabular}{|c|c|c|c|}
\hline & IGF-1 & Bcl-2 & $\beta$-actin \\
\hline Sense & TGGATGCTCTTGAGTTCGTG & CGGCTGGGATGGATTTTGT & CGTGAGAAGATGACCCAGATCA \\
\hline Anti-sense & GTCTTGGGCATGTCAGTGTG & CTGTCCAGTATGAGAGGAA & GGGACAGCACAGCCTGGAT \\
\hline
\end{tabular}


Table 3. Intestinal morphometry from experimental mice.

\begin{tabular}{|c|c|c|c|c|c|c|}
\hline Groups & Villus height & $\mathrm{n}$ & Crypt length & $\mathrm{n}$ & Villus:crypt & $\mathrm{n}$ \\
\hline \multicolumn{7}{|l|}{$\mathrm{APOE}^{+/+}$} \\
\hline Control & $193.7 \pm 24.28$ & 73 & $104.9 \pm 19.54$ & 63 & $1.88 \pm 0.33$ & 63 \\
\hline $5-F U$ & $134.1 \pm 39.00$ & 48 & $131.3 \pm 26.90$ & 40 & $1.07 \pm 0.34$ & 40 \\
\hline $\mathrm{P}$ & $<0.001$ & & $<0.001$ & & $<0.0001$ & \\
\hline Ala-Gln & $145.1 \pm 29.89$ & 55 & $98.33 \pm 13.65$ & 41 & $1.51 \pm 0.37$ & 41 \\
\hline $\mathrm{P}$ & $\mathrm{ns}$ & & $<0.001$ & & $<0.0001$ & \\
\hline \multicolumn{7}{|l|}{$\mathrm{APOE}^{-/-}$} \\
\hline Control & $204 \pm 20.14$ & 71 & $106.8 \pm 15.25$ & 52 & $1.94 \pm 0.30$ & 52 \\
\hline 5-FU & $147.6 \pm 26.7$ & 57 & $141.6 \pm 23.8$ & 31 & $1.03 \pm 0.23$ & 31 \\
\hline $\mathrm{P}$ & $<0.001$ & & $<0.01$ & & $<0.0001$ & \\
\hline Ala-GIn & $169.5 \pm 22.75$ & 36 & $116.2 \pm 25.26$ & 28 & $1.5 \pm 0.44$ & 27 \\
\hline $\mathrm{P}$ & $<0.01$ & & $<0.0001$ & & $<0.0001$ & \\
\hline
\end{tabular}

Data are reported as means $\pm S D$. Villi and crypts were measured only when their full longitudinal axes were found. Results are reported as $\mu \mathrm{m}$. $n$ : total number of measured profiles; control: unchallenged mice; 5-FU: 5-fluorouracil-challenged mice (450 mg/kg, ip); Ala-GIn: 5-FU-challenged mice treated with $100 \mathrm{mM}$ of alanyl-glutamine by gavage. Student's unpaired $t$-test was used for statistical analyses (ns: not significant).

crypt necrosis scores. $\mathrm{P}<0.05$ indicated statistically significant differences.

\section{Results}

\section{Weight curves}

Following the 5-FU challenge (a single $450 \mathrm{mg} / \mathrm{kg}$ ip dose), body weight significantly decreased in all experimental groups and both mouse strains, as early as 3 days post-injection $(P<0.05)$. Ala-GIn treatment $(100 \mathrm{mM})$ did not restore weight to the level of the unchallenged control group. APOE ${ }^{-/-}$mice were slightly less affected than the wild-type controls following the 5-FU challenge (Figure 1).

\section{Blood leukocyte counts}

A significant leukopenia (reduction in the number of leukocytes $/ \mathrm{mm}^{3}$ ) was seen by 5 days following the $5-\mathrm{FU}$ injection, regardless of the mouse genetic background $(P<0.001)$, when compared with unchallenged wild-type controls. This finding confirms the cytotoxic effect of $5-\mathrm{FU}$. This leukopenic effect was not altered nor prevented by Ala-GIn administration ( $P>0.05$; Figure 2).

\section{Analysis of the intestinal surface recovery}

The 5-FU challenge $(450 \mathrm{mg} / \mathrm{kg})$ caused a significant reduction in villus height $(\mathrm{P}<0.001)$ in both $\mathrm{APOE}^{+/+}$ and $\mathrm{APOE}^{-/-}$animals compared with their respective $\mathrm{PBS}$
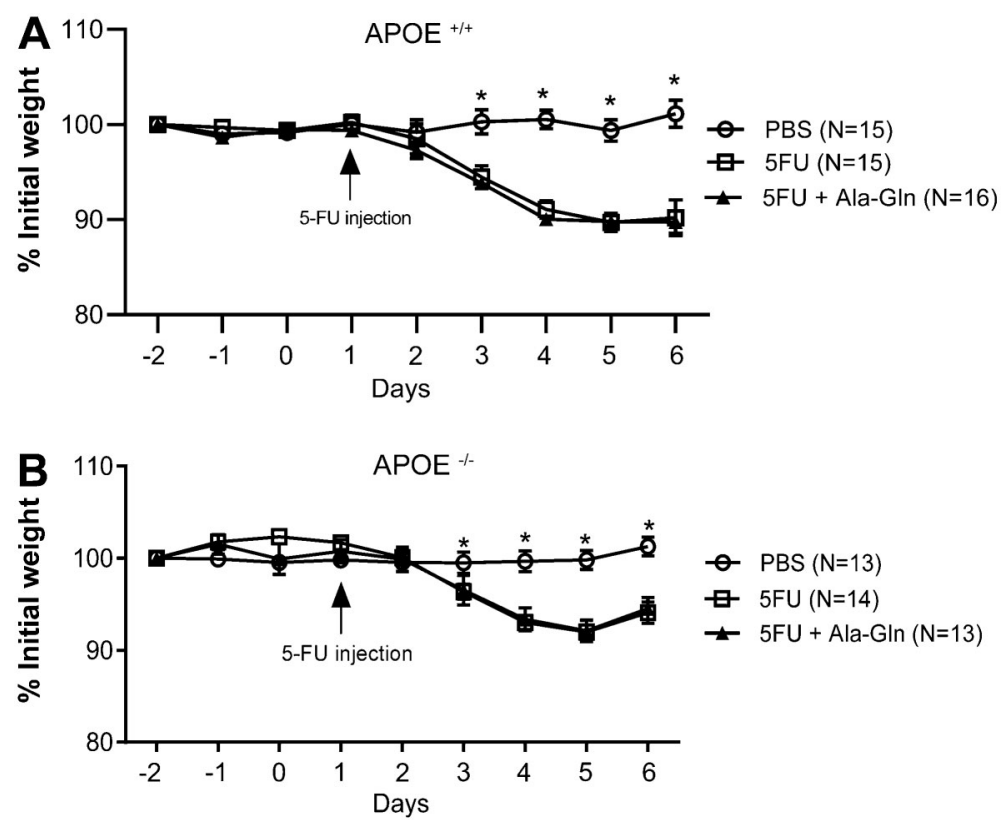

Figure 1. Weight curves of wild-type $\left(\mathrm{APOE}^{+/+}\right)$ $(A)$ and $\mathrm{APOE}$ knockout $\left(\mathrm{APOE}^{-/}\right)$mice $(B)$ following 5 -fluorouracil (5-FU)-induced mucositis and of unchallenged controls receiving phosphate buffered saline (PBS). Data are reported as means \pm SEM. ${ }^{*} \mathrm{P}<0.001$ vs other groups (oneway ANOVA, followed by the Bonferroni multiple test). 


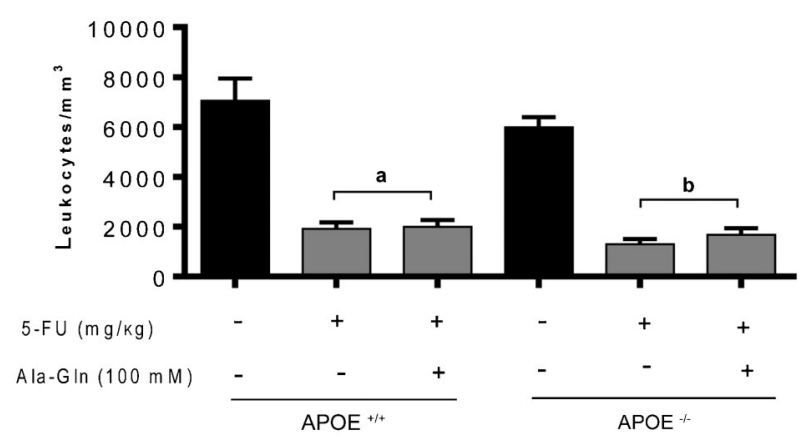

Figure 2. Leukometry results. Mice were anesthetized and blood samples were collected 5 days after 5 -fluorouracil (5-FU) challenge. The total number of white cells was determined after dilution in Turk's solution using a Neubauer chamber. Data are reported as means \pm SEM of the number of leukocytes per $\mathrm{mL}$ of sample $(n=7$ animals/group). ${ }^{\mathrm{a}} \mathrm{P}<0.001$ vs unchallenged wild-type $\left(\mathrm{APOE}^{+/+}\right.$) mice. ${ }^{\mathrm{b}} \mathrm{P}<0.001$ vs unchallenged APOE knockout $\left(\mathrm{APOE}^{-1}\right)$ mice (one-way ANOVA, followed by the Bonferroni multiple test).

controls. Treatment with Ala-GIn (100 mM) enhanced villus height $(P<0.01)$, regardless of apoE deficiency, by 5 days after the 5-FU challenge. However, the villus histology in Ala-Gln-treated mice still included few goblet cells and did not yet resemble that of the unchallenged controls (Figure 3 and Table 3$)$. The crypts of both wild-type $(P<0.001)$ and $\mathrm{APOE}^{-/}(\mathrm{P}<0.01)$ mice given the $5-\mathrm{FU}$ challenge were significantly longer than those of PBS controls, a finding that was partially reversed $(P<0.001)$ or improved $(P<0.0001)$ by Ala-GIn administration (Figure 3 ). As expected, 5-FU induced a significant reduction $(P<0.0001)$ in the morphometric villus/crypt ratio compared with the PBS controls, a finding that was partially reversed $(P<0.0001)$ by Ala-GIn treatment, regardless of the mouse strain (Table 3 ). No between-group differences were found in total ileal villin expression 5 days after 5-FU challenge (data not shown), suggesting that microvilli recovery precedes return of villus height.

\section{Mitotic and apoptotic indexes}

Albeit we found enhanced mitotic crypt index 6 daysfollowing 5-FU-injection, this effect was not significantly different compared to the unchallenged controls both in the wild-type and $\mathrm{APOE}^{(-/)}$mice. Ala-GIn was not able to improve crypt mitotic index compared with the untreated challenged mice in both mouse strains. However, Ala-GIn improved crypt mitotic index only when compared with the unchallenged control $(p<0.01)$. 5-FU challenge remarkably increased crypt apopotic index regardless of the mouse genetic background $(P<0.05)$. Ala-Gln was unable to reduce the crypt apoptotic index following 5-FU challenge (Figure 4).

\section{Necrotic crypt scores}

As expected, unchallenged PBS mice met the zero degree score criteria established for necrotic crypts (see Tables 1 and 4). After being challenged by $5-F U$ (450 mg/kg), both the wild-type and APOE $^{-/-}$mice had a significant increase in ileal necrotic crypt scores $(P<0.028)$ when compared with PBS controls. No differences in crypt necrotic scores were observed between mouse strains after 5-FU challenge. Ala-GIn treatment significantly reduced the necrotic crypt scores only in wild-type mice $(\mathrm{P}<0.04)$ (Table 4$)$.
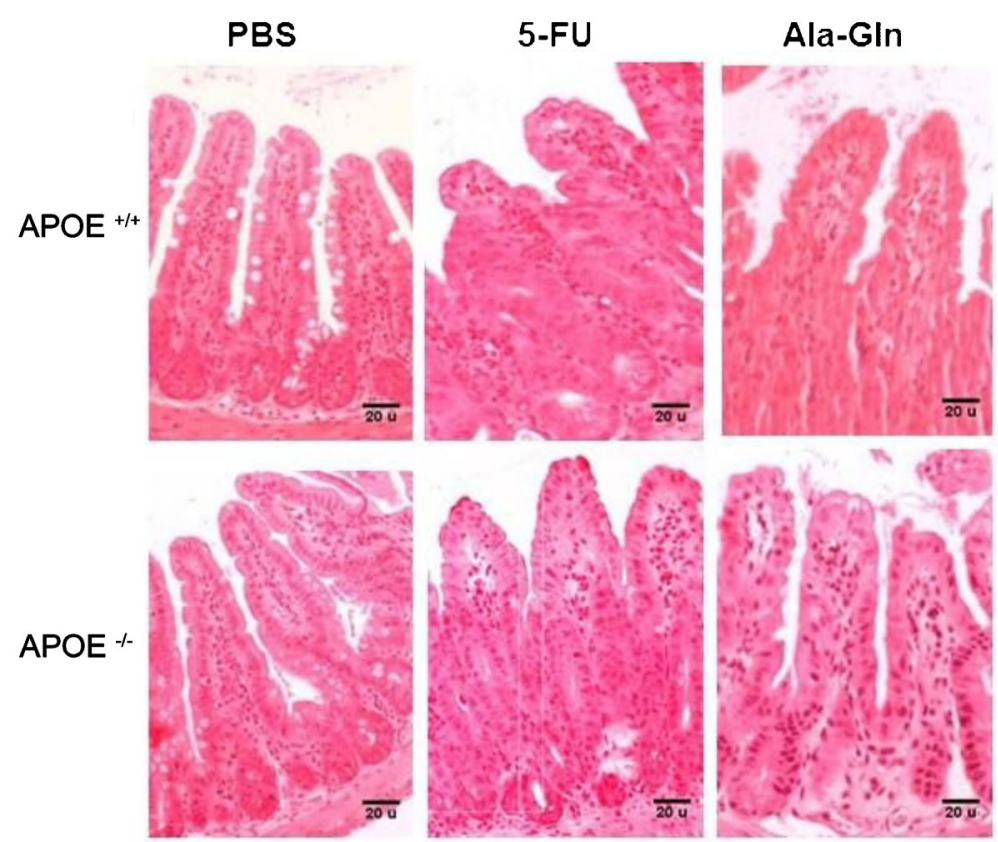

Figure 3. Representative histology of H\&Estained ileal tissue $(100 \times)$ from experimental mice with 5-fluorouracil-induced intestinal mucositis (5-FU, $450 \mathrm{mg} / \mathrm{kg}$, ip, single dose), and mice treated with alanyl-glutamine (Ala-Gln, $100 \mathrm{mM}$ ) or phosphate buffered saline (PBS) via gavage on day 6 post-challenge. 


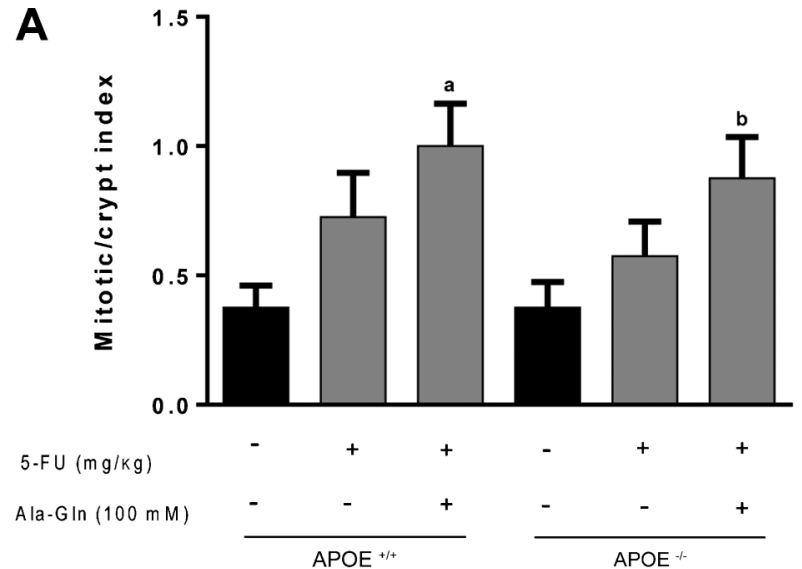

B

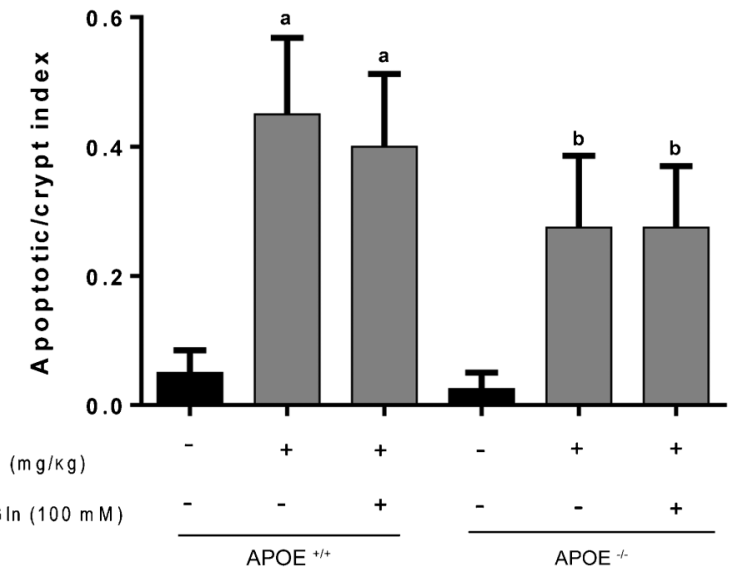

Figure 4. Mean mitotic $(A)$ and apoptotic $(B)$ indexes of H\&Estained ileal crypts from C57BL6J ApoE-knockout $\left(\mathrm{APOE}^{--}\right)$and wild-type ( $\mathrm{APOE}^{+/+}$) mice following 5 -fluorouracil (5-FU)-induced intestinal mucositis $(450 \mathrm{mg} / \mathrm{kg}$, ip, single dose) and treated with the alanyl-glutamine (Ala-Gln, $100 \mathrm{mM}$ ) or phosphate buffered saline (PBS, control) via gavage. At least 10 crypts per animal were analyzed ( $n=4$ animals/group) on the 6th day post-challenge. Data are reported as means \pm SEM. ${ }^{\text {a }} \mathrm{P}<0.001$ vs unchallenged $\mathrm{APOE}^{+/+}$mice; ${ }^{\mathrm{b}} \mathrm{P}<0.05$ vs unchallenged $\mathrm{APOE}^{-/-}$mice (one-way ANOVA and the Bonferroni test).

IGF-1 and BCL-2 quantitative real-time PCR (qPCR)

No statistical differences were found in the ileal IGF-1 and $\mathrm{Bcl}-2$ mRNA transcripts 5 days after 5-FU injection in $\mathrm{APOE}^{+/+}$mice compared with the unchallenged controls. Ala-GIn treatment raised ileal $\mathrm{Bcl}-2$ transcripts following
5-FU challenge in the $\mathrm{APOE}^{-/-}$mice. Noteworthy, 5-FU caused a significant reduction in the ileal IGF-1 mRNA transcripts at 5 days post-challenge only in the $\mathrm{APOE}^{-/}$ mouse strain $(P<0.05)$, an effect that was improved by Ala-Gln (100 mM) treatment (see Figure 5).

\section{Discussion}

Recently, we documented a protective effect of the apoE mimetic peptide COG133 in 5-FU-induced intestinal mucositis, with reduction in the inflammatory cytokine response and improvements in intestinal villus height. We have also confirmed a healing effect of the apoE COG133 in the rat jejunal IEC-6 wound model after 5-FU exposure (15). Ala-GIn is a glutamine compound with increased solubility and stability. It is known to be a key gut-tropic nutrient (19), and has been found to improve healing in the IEC-6 model (14). In this study, we addressed whether Ala-GIn requires apoE for improving intestinal mucosal recovery following 5-FU-induced tissue damage. To test this hypothesis, we used $\mathrm{APOE}^{-/-}$and wild-type $\left(\mathrm{APOE}^{+/+}\right.$) mice with or without 5-FU challenge.

5 -FU induces weight loss in mice mainly due to intestinal mucositis and systemic changes, affecting crypt cell turnover, and ultimately leading to reduced villus absorptive surface area (20). 5-FU-challenged mice develop dehydration, anorexia and exhibit a $20 \%$ weight loss 6 days after $5-$ FU injection, in addition to profound leukopenia (4). It is recognized that myelotoxicity is one of the major side effects in patients receiving 5-FU treatment (21). Leukopenia and neutropenia are significantly correlated with the pharmacokinetic parameters of 5-FU metabolism, with increase in 5-FU exposure leading to greater toxicity. Moreover, leukopenia and neutropenia are inversely correlated with peripheral blood mononuclear cell telomere length (22). As shown previously by our earlier study, Ala-GIn treatment could not promote weight gain in 5-FU challenged mice (5). In this study, C57BL6J APOE ${ }^{+/+}$and APOE $^{-/-}$mice showed significant weight loss compared with PBS controls by day 3 after 5-FU challenge. Likewise, we could not find a benefit of Ala-GIn treatment in improving weight gain following 5-FU challenge, independent of the genetic background of the tested mice. In support of our findings, one small clinical trial using intravenous alanyl-glutamine infusion in patients with neck and head cancer undergoing chemoradiotherapy (radiotherapy daily up to $70 \mathrm{~Gy}$, plus cisplatin/5-fluoruracil once a week) found improvement of oral mucositis after AlaGln treatment, but without change in weight (23).

Table 4. Necrotic crypt scoring in mice with or without 5-fluorouracil challenge.

\begin{tabular}{lccc}
\hline Groups & PBS $(\mathrm{n}=4)$ & $5-\mathrm{FU}(\mathrm{n}=4)$ & Ala-Gln $(\mathrm{n}=6)$ \\
\hline Wild-type & $0(0-0)$ & $2(2-2)^{\star}$ & $1.5(0-2)^{\star}$ \\
ApoE $^{-/-}$ & $0(0-0)$ & $1.5(1-2)^{*}$ & $1.5(1-2)$ \\
\hline
\end{tabular}

PBS: phosphate buffered saline; 5-FU: 5-fluorouracil. * $\mathrm{P}<0.05$ compared to PBS control (Mann-Whitney test). 

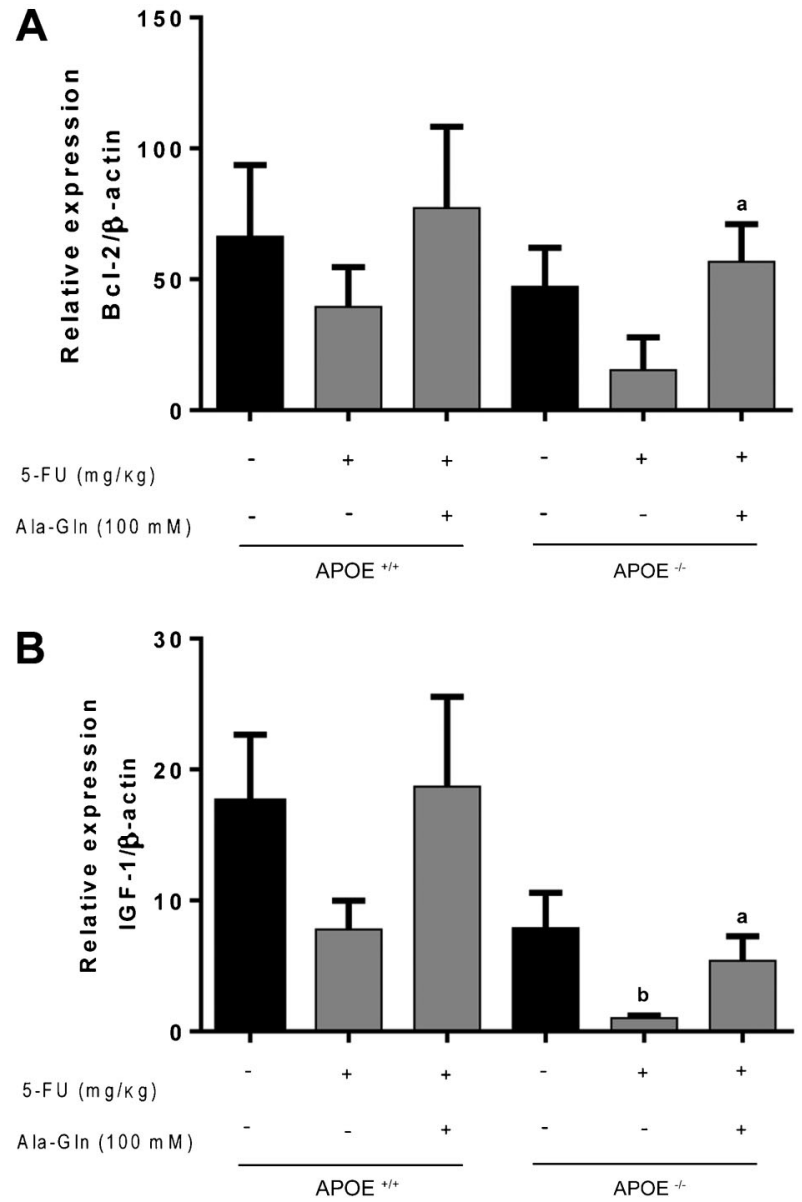

Figure 5. Quantitative real-time PCR for B-cell lymphoma 2 (Bcl-2) and insulin-like growth factor-1 (IGF-1) mRNA transcripts from C57BL6J ApoE-knockout (APOE ${ }^{-/}$) and wild-type (APOE ${ }^{+/+}$) mice challenged by 5 -fluorouracil (5-FU)-induced intestinal mucositis $(450 \mathrm{mg} / \mathrm{kg}$, ip, single dose) on the day 6 post-challenge and treated with alanyl-glutamine (Ala-Gln, $100 \mathrm{mM}$ ) or phosphate buffered saline (PBS, control) via gavage. Data are reported as means \pm SEM. ${ }^{\text {a }}<<0.05$ vs 5 -FU-challenged group. ${ }^{b} \mathrm{P}<0.05$ vs unchallenged control (one-way ANOVA and the Bonferroni test).

Soares et al. (20) challenged Wistar rats with the same $450 \mathrm{mg} / \mathrm{kg} \mathrm{5-FU}$ dose used in this study, and reported prolonged weight decrements up to 15 days after 5-FU challenge, compared with unchallenged controls. Therefore, improvements in intestinal mucositis precede weight catchup; however it seems that even with improved villus height in Ala-GIn-treated mice by the sixth post-challenge day, nutrient absorption may still have been too low to support weight recovery. Although villi were taller at that time, villus histology did not yet resemble that of the controls. Goblet cells (in the villus and crypts) and Paneth cells (in the crypts) were still scarce at 6 days post-challenge in the 5-FU-treated mice regardless of the presence of the APOE gene.

In a study by Carneiro-Filho et al. (19), treatment with Ala-GIn (100 mM), but not with $\mathrm{Gln}(100 \mathrm{mM})$, ameliorated intestinal morphometry (Ala-GIn improved villous area) and increased the crypt mitotic index following 5-FU challenge. Our findings did not include an increase in crypt mitotic index following Ala-GIn treatment. This discrepancy may be due to the difference in the mouse strain used. Also, the higher 5-FU dose used in our study $(450 \mathrm{mg} / \mathrm{kg}$ ip, single dose) may have lowered the crypt mitotic rate for a longer time.

The crypt hyperplasia present on day 6 after 5-FU challenge represents a compensatory phenomenon to renew the intestinal epithelium and restore the absorptive surface compromised by chemotherapy. Ala-GIn treatment improved villus height and villus/crypt ratio in both $\mathrm{APOE}^{+/+}$ and $\mathrm{APOE}^{-/-}$mice, suggesting that the Ala-GIn mucosal healing effect occurs regardless of apoE deficiency.

Villin is a structural component of microvilli forming the brush border of the small intestine and plays a key role in maintaining brush border organization by binding to F-actin in a network of filaments (24). The brush border acts to increase the absorptive surface of the enterocytes. Although villus blunting was seen in 5-FU-challenged mice, the villin/ actin ratio was not significantly different between groups, suggesting sufficient protein recovery 5 days after the administration of 5-FU. Protein recovery precedes the recovery of the villus height.

Circulating factors, such as IGF-1, have been implicated in the control of intestinal epithelial proliferation $(25,26)$ through interactions with gut trophic nutrients, multiple hormones, and growth factors (27). Furthermore, oral IGF-1 treatment has been shown to improve Gln transport in piglet enterocytes (28). APOE ${ }^{-l-}$ (but not wild-type) mice challenged by $5-F U(450 \mathrm{mg} / \mathrm{kg})$ had reduced IGF-1 mRNA transcription, suggesting that apoE could influence intestinal IGF-1 levels. This effect was reversed by Ala-GIn treatment. At this stage, this result remains unexplained. An earlier study from our group documented impaired intestinal IGF-1 expression following refeeding in $\mathrm{APOE}^{-/}$subjected to maternal-offspring separation (29).

One explanation for the apoE effects on IGF-1 levels may be related to a potential apoE protective effect on the liver. ApoE may redirect lipopolysaccharide (LPS) (from the leaky gut) from Kupffer cells to liver parenchymal cells, improving LPS clearance from circulation via bile (30), which may improve liver and intestinal IGF-1 levels. That hypothesis should be further explored in future studies using the 5-FU induced-intestinal mucositis model. Another interesting approach would be to assess whether the intestinal microbiome is changed by Ala-GIn and how much that is affected by apoE deficiency. Probiotics have been used recently to improve 5-FU intestinal mucositis (31) and GIn has been shown to activate the innate immune system through the intestinal microbiome (11).

Cool et al. (32) investigated a 7-day infusion $(4.3 \mathrm{mg} /$ $\mathrm{kg}$ daily) of IGF-I to Sprague-Dawley rats challenged by $5-F U(150 \mathrm{mg} / \mathrm{kg}, \mathrm{ip})$. They reported that $5-\mathrm{FU}$ reduced the villus height in the duodenum by $23 \%$, in the jejunum 
by $20 \%$, and in the ileum by $30 \%$ at 48 -h post-challenge, with an 87-times increase in the crypt apoptotic rate. These effects were substantially less pronounced in IGF-I pretreated rats.

An increase in the apoptotic rate in the crypts (which was not improved by the administration of GIn or Ala-GIn) has been found on day 1 , and to a lesser extent on day 6 , after 5-FU injection, compared with a PBS control (5). In addition, Yasuda et al. (33) have documented that the number of apoptotic, caspase-3- and caspase-8-activated cells increased $24 \mathrm{~h}$ after the first 5 -FU administration.

In agreement with those results, we found a significant increase in the apoptotic crypt index at day 6 post-challenge in both $\mathrm{APOE}^{--}$and wild-type mice, an effect that was not reversed by Ala-GIn treatment. To evaluate this effect at the molecular level, we assessed the antiapoptotic Bcl-2 mRNA transcripts by q PCR. Ala-Gln enhanced the Bcl-2

\section{References}

1. Keefe DM, Brealey J, Goland GJ, Cummins AG. Chemotherapy for cancer causes apoptosis that precedes hypoplasia in crypts of the small intestine in humans. Gut 2000; 47: 632637, doi: 10.1136/gut.47.5.632.

2. Graham JS, Cassidy J. Adjuvant therapy in colon cancer. Expert Rev Anticancer Ther 2012; 12: 99-109, doi: 10.1586/ era.11.189.

3. Soares PM, Mota JM, Souza EP, Justino PF, Franco AX, Cunha FQ, et al. Inflammatory intestinal damage induced by 5-fluorouracil requires IL-4. Cytokine 2013; 61: 46-49, doi: 10.1016/j.cyto.2012.10.003.

4. Wu Z, Han X, Qin S, Zheng Q, Wang Z, Xiang D, et al. Interleukin 1 receptor antagonist reduces lethality and intestinal toxicity of 5-fluorouracil in a mouse mucositis model. Biomed Pharmacother 2011; 65: 339-344, doi: 10.1016/ j.biopha.2011.04.013.

5. Carneiro-Filho BA, Oriá RB, Wood RK, Brito GA, Fujii J, Obrig $\mathrm{T}$, et al. Alanyl-glutamine hastens morphologic recovery from 5-fluorouracil-induced mucositis in mice. Nutrition 2004; 20 : 934-941, doi: 10.1016/j.nut.2004.06.016.

6. Longley DB, Harkin DP, Johnston PG. 5-fluorouracil: mechanisms of action and clinical strategies. Nat Rev Cancer 2003; 3: 330-338, doi: 10.1038/nrc1074.

7. Goessling W, Mayer RJ. Systemic treatment of patients who have colorectal cancer and inflammatory bowel disease. Gastroenterol Clin North Am 2006; 35: 713-727, doi: 10.1016/ j.gtc.2006.07.006.

8. Drozdowski L, Thomson AB. Intestinal mucosal adaptation. World J Gastroenterol 2006; 12: 4614-4627.

9. Ziegler TR, Evans ME, Fernandez-Estivariz C, Jones DP. Trophic and cytoprotective nutrition for intestinal adaptation, mucosal repair, and barrier function. Annu Rev Nutr 2003; 23: 229-261, doi: 10.1146/annurev.nutr.23.011702. 073036.

10. Penny ME, Marin RM, Duran A, Peerson JM, Lanata CF, Lonnerdal B, et al. Randomized controlled trial of the effect of daily supplementation with zinc or multiple micronutrients on the morbidity, growth, and micronutrient status of young Peruvian children. Am J Clin Nutr 2004; 79: 457-465. transcription activity compared with the control only in $\mathrm{APOE}^{-/-}$mice challenged by $5-\mathrm{FU}$. It is noteworthy that GIn deprivation can lead to increased intestinal apoptosis with involvement of specific caspases (34-36).

In summary, our overall findings suggest an apoEindependent Ala-GIn effect on intestinal mucosa improvement following 5-FU challenge because this nutrient improved the 5-FU intestinal tissue damage in ApoEgenetically depleted mice. The potential synergistic effect of ApoE and Ala-GIn supplementation warrants further studies.

\section{Acknowledgments}

The authors would like to thank Fundação Cearense de Apoio ao Desenvolvimento Científico e Tecnológico (FUNCAP) and CNPq for funding support.

11. Ren W, Duan J, Yin J, Liu G, Cao Z, Xiong X, et al. Dietary L-glutamine supplementation modulates microbial community and activates innate immunity in the mouse intestine. Amino Acids 2014; 46: 2403-2413, doi: 10.1007/s00726-014-1793-0.

12. Zhou $\mathrm{X}$, Wu $\mathrm{X}$, Yin $\mathrm{Y}$, Zhang $\mathrm{C}$, He L. Preventive oral supplementation with glutamine and arginine has beneficial effects on the intestinal mucosa and inflammatory cytokines in endotoxemic rats. Amino Acids 2012; 43: 813-821, doi: 10.1007/s00726-011-1137-2.

13. Brito GA, Carneiro-Filho B, Oriá RB, Destura RV, Lima AA, Guerrant RL. Clostridium difficile toxin A induces intestinal epithelial cell apoptosis and damage: role of GIn and AlaGIn in toxin A effects. Dig Dis Sci 2005; 50: 1271-1278, doi: 10.1007/s10620-005-2771-x.

14. Braga-Neto MB, Warren CA, Oriá RB, Monteiro MS, Maciel AA, Brito GA, et al. Alanyl-glutamine and glutamine supplementation improves 5-fluorouracil-induced intestinal epithelium damage in vitro. Dig Dis Sci 2008; 53: 2687-2696, doi: $10.1007 /$ s10620-008-0215-0.

15. Azevedo OG, Oliveira RA, Oliveira BC, Zaja-Milatovic S, Araujo CV, Wong DV, et al. Apolipoprotein E COG 133 mimetic peptide improves 5-fluorouracil-induced intestinal mucositis. BMC Gastroenterol 2012; 12: 35, doi: 10.1186/ 1471-230X-12-35.

16. Azevedo OG, Bolick DT, Roche JK, Pinkerton RF, Lima AA, Vitek MP, et al. Apolipoprotein E plays a key role against cryptosporidial infection in transgenic undernourished mice. PLoS One 2014; 9: e89562, doi: 10.1371/journal.pone. 0089562.

17. Oriá RB, Patrick PD, Blackman JA, Lima AA, Guerrant RL. Role of apolipoprotein E4 in protecting children against early childhood diarrhea outcomes and implications for later development. Med Hypotheses 2007; 68: 1099-1107, doi: 10.1016/j.mehy.2006.09.036.

18. Mitter SS, Oriá RB, Kvalsund MP, Pamplona P, Joventino ES, Mota RM, et al. Apolipoprotein E4 influences growth and cognitive responses to micronutrient supplementation in shantytown children from northeast Brazil. Clinics 2012; 67: 11-18, doi: 10.6061/clinics/2012(01)03. 
19. Carneiro-Filho BA, Bushen OY, Brito GA, Lima AA, Guerrant $\mathrm{RL}$. Glutamine analogues as adjunctive therapy for infectious diarrhea. Curr Infect Dis Rep 2003; 5: 114-119, doi: 10.1007/ s11908-003-0046-2.

20. Soares PM, Mota JM, Gomes AS, Oliveira RB, Assreuy AM, Brito GA, et al. Gastrointestinal dysmotility in 5-fluorouracilinduced intestinal mucositis outlasts inflammatory process resolution. Cancer Chemother Pharmacol 2008; 63: 91-98, doi: 10.1007/s00280-008-0715-9.

21. Malet-Martino $M$, Jolimaitre $P$, Martino $R$. The prodrugs of 5-fluorouracil. Curr Med Chem Anticancer Agents 2002; 2: 267-310, doi: 10.2174/1568011023354146.

22. Garg MB, Lincz LF, Adler K, Scorgie FE, Ackland SP, Sakoff JA. Predicting 5-fluorouracil toxicity in colorectal cancer patients from peripheral blood cell telomere length: a multivariate analysis. $\mathrm{Br} J$ Cancer 2012; 107: 1525-1533, doi: 10.1038/bjc.2012.421.

23. Cerchietti LC, Navigante AH, Lutteral MA, Castro MA, Kirchuk $\mathrm{R}$, Bonomi M, et al. Double-blinded, placebo-controlled trial on intravenous L-alanyl-L-glutamine in the incidence of oral mucositis following chemoradiotherapy in patients with headand-neck cancer. Int J Radiat Oncol Biol Phys 2006; 65: 13301337, doi: 10.1016/j.jijrobp.2006.03.042.

24. Athman R, Louvard D, Robine S. The epithelial cell cytoskeleton and intracellular trafficking. III. How is villin involved in the actin cytoskeleton dynamics in intestinal cells? Am J Physiol Gastrointest Liver Physiol 2002; 283: G496-G502.

25. Gordon PV, Paxton JB, Herman AC, Carlisle EM, Fox NS. Igf-I accelerates ileal epithelial cell migration in culture and newborn mice and may be a mediator of steroid-induced maturation. Pediatr Res 2004; 55: 34-41, doi: 10.1203/01.PDR.0000 100461.00878.75.

26. Chen K, Nezu R, Wasa M, Sando K, Kamata S, Takagi Y, et al. Insulin-like growth factor-1 modulation of intestinal epithelial cell restitution. JPEN J Parenter Enteral Nutr 1999; 23: S89-S92, doi: 10.1177/014860719902300522.

27. Bortvedt SF, Lund PK. Insulin-like growth factor 1: common mediator of multiple enterotrophic hormones and growth factors. Curr Opin Gastroenterol 2012; 28: 89-98, doi: 10.1097/MOG.0b013e32835004c6.

28. Alexander AN, Carey HV. Insulin-like growth factor-I stimulates $\mathrm{Na}^{+}$-dependent glutamine absorption in piglet enterocytes. Dig Dis Sci 2002; 47: 1129-1134, doi: 10.1023/ A:1015010728696.

29. Oriá RB, Vieira CMG, Pinkerton RC, De Castro-Costa CM, Lopes MB, Hussaini I, et al. Apolipoprotein E knockout mice have accentuated malnutrition with mucosal disruption and blunted insulin-like growth factor responses to refeeding. Nutrition Res 2007; 26: 427-435, doi: 10.1016/j.nutres.2006. 06.020 .

30. Rensen PC, Oosten M, Bilt E, Eck M, Kuiper J, Berkel TJ. Human recombinant apolipoprotein $E$ redirects lipopolysaccharide from Kupffer cells to liver parenchymal cells in rats In vivo. J Clin Invest 1997; 99: 2438-2445, doi: 10.1172/JCl119427.

31. Justino PF, Melo LF, Nogueira AF, Costa JV, Silva LM, Santos $\mathrm{CM}$, et al. Treatment with Saccharomyces boulardii reduces the inflammation and dysfunction of the gastrointestinal tract in 5-fluorouracil-induced intestinal mucositis in mice. $\mathrm{Br} J$ Nutr 2014; 111: 1611-1621, doi: 10.1017/S0007114513004248.

32. Cool JC, Dyer JL, Xian CJ, Butler RN, Geier MS, Howarth GS. Pre-treatment with insulin-like growth factor-I partially ameliorates 5-fluorouracil-induced intestinal mucositis in rats. Growth Horm IGF Res 2005; 15: 72-82, doi: 10.1016/j.ghir. 2004.12.002.

33. Yasuda M, Kato S, Yamanaka N, limori M, Matsumoto K, Utsumi D, et al. 5-HT(3) receptor antagonists ameliorate 5 -fluorouracil-induced intestinal mucositis by suppression of apoptosis in murine intestinal crypt cells. $\mathrm{Br} \mathrm{J}$ Pharmacol 2013; 168: 1388-1400, doi: 10.1111/bph.12019.

34. Papaconstantinou HT, Hwang KO, Rajaraman S, Hellmich MR, Townsend CM Jr, Ko TC. Glutamine deprivation induces apoptosis in intestinal epithelial cells. Surgery 1998; 124: 152-159, doi: 10.1016/S0039-6060(98)70115-1.

35. Carneiro BA, Fujii J, Brito GA, Alcantara C, Oriá RB, Lima AA, et al. Caspase and bid involvement in Clostridium difficile toxin A-induced apoptosis and modulation of toxin $A$ effects by glutamine and alanyl-glutamine in vivo and in vitro. Infect Immun 2006; 74: 81-87, doi: 10.1128/IAI.74.1.81-87. 2006.

36. Papaconstantinou HT, Chung DH, Zhang W, Ansari NH, Hellmich MR, Townsend CM Jr, et al. Prevention of mucosal atrophy: role of glutamine and caspases in apoptosis in intestinal epithelial cells. J Gastrointest Surg 2000; 4: 416423, doi: 10.1016/S1091-255X(00)80022-0. 